\title{
The rehabilitation nurse then and now: From technical support to human potential catalyst by Caring- Disability Creation Process Model in an interprofessional team
}

\author{
Daphney St-Germain \\ Université Laval, Québec, Canada. \\ Correspondence: Daphney St-Germain. Address: Université Laval, Québec, Canada. \\ Email: daphney.st-germain@fsi.ulaval.ca \\ Received: February 25, 2014 \\ Accepted: April 1, 2014 \\ Online Published: April 24, 2014 \\ DOI : $10.5430 /$ jnep.v4n7p54 \\ URL: http://dx.doi.org/10.5430/jnep.v4n7p54
}

\begin{abstract}
This article traces the historical development of the role of the rehabilitation nurse. This development highlights the importance of the caring approach in the humanization of nursing cares. The Caring-DCP model (Disability Creation Process) presents effectively a relational approach that combines care and rehabilitation which could be efficient in this kind of setting. The alliance of these two concepts provides to nurses a unique way to work in the bosom of the interprofessional team that focusing on the patient social participation.
\end{abstract}

\section{Key words}

Rehabilitation nurse, Disability Creation Process (DCP) Model, Caring-DCP Model, Caring approach, Rehabilitation setting, Patients’ social integration, Patients’ social participation, Interprofessional collaboration

\section{I ntroduction}

In the last 50 years, the role of nurses has evolved and diversified. The emancipation of the role, the specialization of the practice and nurses' recognition of their own role are some examples of these changes. It was Virginia Henderson ${ }^{[1]}$ who suggested that nurses are, or at least have the potential to be, "rehabilitators par excellence". But what does that role involve? What perspective could we have on this role? The rehabilitation nurse's role has grown over the years, but it remains relatively unknown, especially regarding the all potential of its caring aspect. The Caring-DCP (Disability Creation Process) model will reveal an efficient way to promote humanization of care in a rehabilitation setting. Moreover, in this context, interprofessional collaboration and patient social participation issues need to be debated as well.

\section{Historical development of the role}

According to Wirotius ${ }^{[2]}$, the role of the rehabilitation nurse developed in lockstep with the history of rehabilitation. In the early period of rehabilitation as a specialty, secular nurses were gradually taking over the role of nuns in health care. The two world wars highlighted nurses' devotion and bravery on the battlefield. Their focus was on restoring soldiers to a state of fitness so they could either return to battle or be sent home ${ }^{[3]}$. At this time, interventions focused largely on disability 
and physical/functional improvements ${ }^{[4]}$. Thus, this period represented the first appearance of the rehabilitation nurse. From those beginnings, the need for rehabilitation became increasingly obvious in the field of physical impairments ${ }^{[5]}$, and a need was perceived to move to a new concept of care. The therapeutic relation between nurse and patient evolved such that patient care was no longer centered on the disease itself but on the individual as a unique entity.

This modification of the concept of care is still relevant today. Several care approaches based on different nursing models are now available. In recent years, the health care system has paid particular attention to the humanization of care ${ }^{[6]}$. The role of the rehabilitation nurse has developed accordingly but remains little known to non-specialists.

Matter and Rugraff ${ }^{[7]}$ define the role of rehabilitation nurses as follows: The rehabilitation nurse cares for patients suffering from a temporary or permanent disability, which necessitates not only technical skills but also interpersonal and educational competencies, since the illness or accident causes the patient to lose autonomy, either partially or totally.

The clinical aspect of the nurse's role is subdivided into several dimensions: basic care (activities of daily life), technical care (vital signs, dressings, catheterization, medication, etc.), specialized care (transfers, prevention and treatment of bedsores, etc.) and ultra-specialized care (dysphagia, bladder and intestinal training, etc.), with the ultimate aim of achieving maximum functional autonomy for the patient. These different kinds of care are associated with a relationship with a person, who is generally coping with the process of grieving at the time ${ }^{[8]}$. In the context of rehabilitation, the concept of caring is omnipresent in the nurse's approach to the patient. This environment is a propitious one for individual care, and a humanistic approach to providing this care contributes to the promotion and preservation of human dignity ${ }^{[9]}$.

\section{The caring approach}

The caring approach occupies an important place within nursing practice. It has been applied by the nursing departments of many rehabilitation centers in Quebec. For patients, this approach means care that respects their human dignity while seeking to optimize the development of their full potential ${ }^{[10]}$. Thus, the patient is considered holistically, with body, mind and spirit being addressed simultaneously. By applying a caring philosophy, nurses refine their practice by providing care that is specific to patients' individuality while respecting their learning speed and taking account of their life plans for the short, medium and long term. The focus is not on specific treatments but on the objective that is targeted. In most cases, this objective can be summarized as a certain level of well-being and growth in the patient over the long term ${ }^{[11,12]}$.

Jean Watson, the initiator of this approach, suggests that the caring approach is the essence of nursing ${ }^{[13,14]}$. According to Watson, the nurse's role is to:

- Establish a caring relationship with patients

- $\quad$ Treat patients as holistic beings (body, mind and spirit)

- Display unconditional acceptance

- $\quad$ Treat patients with a positive regard

- $\quad$ Promote health through knowledge and intervention

- Spend uninterrupted time with patients: “caring moments"

In the philosophy of caring, nurses refine their practice by providing specific care by taking the patient's body, mind and soul into consideration, along with the environment in which care is provided.

\section{An example of caring in the rehabilitation context}

This example highlights the alternatives offered in a clinical intervention with a patient. By taking the patient as a whole person into consideration, nurses can contribute positively or negatively to his or her rehabilitation based on the choices 
they make. Take, for example, a patient who regularly calls to complain about being unable to sleep. The nurse could decide to administer a medication immediately or take a few minutes to discuss the causes of the patient's insomnia with him or her. The first option would lead to sleep immediately, but could result in problems such as side effects of medication interactions or decreased nighttime care routines. The second option will take more time; however, greater patient satisfaction is likely to result. In addition, this option would enhance the progress of the patient's rehabilitation. This type of intervention has the objective of focusing on patients and accompanying them in developing skills so that they can move toward optimum social participation.

While still being concerned with patients' situation "here and now", as well as what will happen to them in the future, the nurse who adopts a caring approach will strive to prevent undesirable events in the care environment or after the patients leave it. In this sense, caring contributes to preventing readmissions in the health care sector and thus to improving productivity and many aspects of the organization of care ${ }^{[15]}$. Thus, this humanistic approach is valuable for the patient, for the nurses and for the health care system, because it may promote quality care that would be particularly beneficial for patients in rehabilitation.

\section{Rehabilitation care and the role of nurses}

Physical rehabilitation care differs from other kinds of health care because it cannot be defined as constituting either long-term or acute care. However, as in all kinds of health care, nurses are the professionals who are the closest to patients, and thus the ones who are most aware of the latest developments in the patients' condition. Nurses have a preferential relationship with patients, 24 hours a day, 365 days a year. They are the cornerstone of the team surrounding the patient.

Rehabilitation is a topic of considerable interest given that it is a key step in reducing disability and preventing recurrence while the individual returns to his or her initial level, or nearly so. This kind of care requires from the nurse, among other things, increasing knowledge of the administration of antibiotics, the use of technical assistance, and post-operative care. However, all these things can be claimed to be the responsibility of nurses in any field. It is difficult to define how rehabilitation nurses' practice compares to other specialties ${ }^{[16]}$. In fact, nurses play an important role but their contribution to rehabilitation is largely undiscussed in the literature.

Some studies have reported on the role of rehabilitation nurses. Kirkevold ${ }^{[17]}$ identified four therapeutic rehabilitative nursing functions: interpreting, consoling, conserving and integrating. Similarly, Long et al. ${ }^{[16]}$ reported six interlinked roles for nurses: assessment, coordination and communication, technical and physical care, therapy integration and therapy carry-on, emotional support, and involving the family. Pryor and Smith ${ }^{[18]}$ developed a framework for Australian rehabilitation nurses that identified seven domains of practice: the rehabilitation approach, the teaching and coaching role, observation, assessment and interpretation, administering and monitoring therapeutic interventions, management of rapidly changing situations, management, advocacy and coordination, and monitoring and ensuring the quality of health care practices. However, despite those various approaches, the role of the rehabilitation nurse is far from straightforward, given the long duration of rehabilitation and the uncertainty of its outcomes ${ }^{[19]}$.

In fact, the variety of disabilities makes this area of care more complex than many others. Rehabilitation services are offered to patients of all ages with neurological, motor, visual, hearing, speech or language impairments. Thus, a rehabilitation nurse is responsible for different patients suffering from different kinds of temporary or permanent disabilities. Rehabilitation is important because it allows patients to move forward from being unable to perform the majority of their personal care tasks to the recovery of normal everyday activities. To achieve this, patients must go through a long and tedious process that requires daily work. Thus, patients must collaborate significantly in their own care process, so that they support their own rehabilitation and become more able to exercise their decision-making power and regain their independence ${ }^{[15]}$. This active collaboration by patients is key to their social participation, which ensures their 
full development in society throughout their lifetime. By collaborating in the rehabilitation process, they will be able to develop skills that will help in their social involvement and interactions when they return home.

Like active collaboration by the patient, the rehabilitation care approach is another determining factor. One of the five characteristics of effective rehabilitation mentioned by Pryor and Buzio ${ }^{[20]}$ is that nurses should adopt a "hands-off" approach instead of a "doing for” or “doing to” approach. By adopting this approach, nurses focus on patients' abilities in order to elicit their full potential. Rehabilitation nurses see patients as a whole and thus seek to accompany them and tailor treatments to each patient's life experience and individual identity. They strive to meet each person's specific needs and expectations in a rehabilitation setting, and establish a reciprocal relationship based on authentic altruistic values in order to promote the individual's social integration and participation ${ }^{[21]}$. This attitude is guided by a humanistic method such as the caring approach.

\section{From Disability Creation Process Model}

In the area of professional rehabilitation practice, it should be noted that the Disability Creation Process (DCP) model ${ }^{\text {[2] }}$ was adopted in 2001 by Quebec's Ministry of Health and Social Services in its policies concerning physical and intellectual disabilities. Among other things, this model makes it possible to identify and explain the causes and consequences of illnesses, trauma and other factors compromising a person's integrity or development. The DCP model provides a perspective that highlights the fact that successfully engaging in living habits and social participation depends on personal and environmental factors. That means that a disability cannot be reduced to the resulting physical limitations alone but becomes the product of a considerable environmental component that interferes with the person's social participation. The Figure 1 below presented the DCP model.

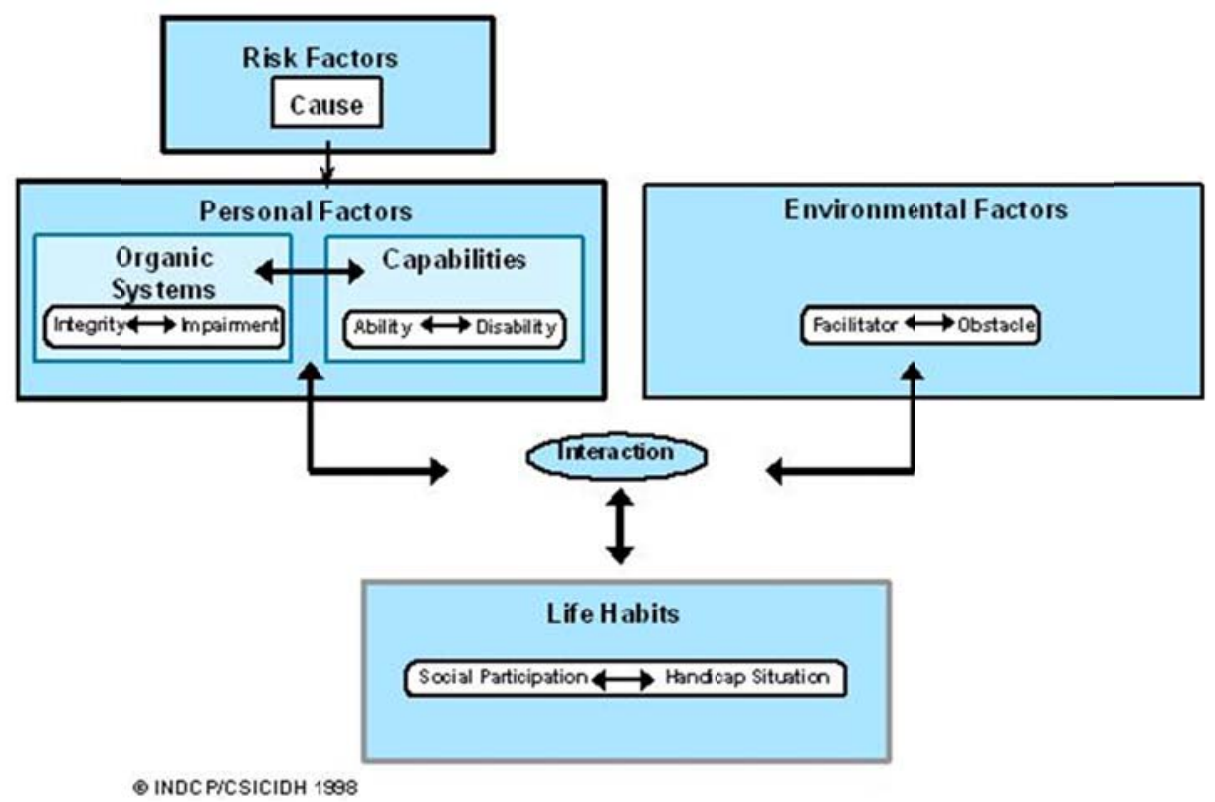

Figure 1. The DCP Model

With a concern for promoting an optimal rehabilitation approach, the caring philosophy can be applied through the DCP model. Both these conceptual models were formulated to consider people's future and accompany them in the development of their competencies so that they move toward optimal social participation. When combined in this way, the Caring-DCP model makes it possible to integrate a nursing care component with a rehabilitation component ${ }^{[11,12]}$. Thus, both models can have a common and coherent vision of the purpose of rehabilitation, namely a representation of the nurse in action with the patient in a rehabilitation situation. The Caring-DCP model offers valuable support for rehabilitation 
nurses so they can set appropriate intervention objectives for the patient's life experience and projects. Briefly, the adoption of such a model by nurses who combine a humanist approach, as suggested by the Caring model, with support for patients in achieving optimal social participation, as stipulated by the DCP, allows them to create a unique link between care and rehabilitation. This innovative relationship is intended to ensure a certain well-being over the long term that allows for full social participation and, consequently, a certain degree of security from a holistic point of view as well.

\section{What about patients' social integration and participation?}

Nursing care in a rehabilitation context is organized around the patient, his or her living habits and his or her capacity for active involvement in the community. Thus, the philosophy of the Institut de réadaptation en déficience physique de Québec (IRDPQ) focuses on patients' integration and participation. Staff members (psychologists, occupational therapists, pharmacists, etc.) are urged to keep this focus in mind, and nurses play a key role in implementing this philosophy.

The organization of nursing work takes account of the patient's expectations and needs so that personal care, the compensation measures used to mitigate the disability, and/or the development of new living habits create the most acceptable lifestyle for him or her and the one that corresponds most closely with what he or she considers to be a good quality of life. Seen from this angle, the organization of rehabilitation care must be flexible, open to change and ready to adapt to each individual's needs ${ }^{[8]}$. Nursing staff will favor the person's ongoing social integration by reinforcing and encouraging him or her during the learning process. Because it has been proven that experimentation in the patient's living environment makes a positive contribution to rehabilitation, it is important to encourage outings. In that way, the person's social network is better preserved and success factors and obstacles to integration can be identified more easily.

The current context of rehabilitation care can be defined as follows: early arrival of people who need significant technical care, greater need for infection prevention, lack of resources, unstable teams, etc. However, such conditions should not prevent nurses from remaining vigilant and keeping the specific dimension of rehabilitation in mind. Needless to say, these working conditions affect employers as well. Employers must ensure that nurses' working conditions and the organization of work are conducive to rehabilitation care. As Boivin ${ }^{[8]}$ points out, it is desirable for managers' and staff members' values, philosophy and vision to be coherent. The program-based approach, management based on shifts, and care delivery system can cause certain difficulties. Communication is then key to ensuring coherent management of nursing care. The IRDPQ views nursing care within an interdisciplinary context in which the patient (and his or her family) is at the center and makes the decisions regarding what care shall be received. In fact, one of the IRDPQ's missions is patient integration and social participation. This psychosocial vision allows for an easier return to the community.

\section{An essential interprofessional collaboration process within the Caring-DCP Model}

Interprofessional collaboration has always been inherent in the domain of physical rehabilitation. Indeed, it is a field in which professionals from several different fields (physiotherapists, physicians, nurses, social workers, occupational therapists, etc.) pool their strengths and knowledge in order to effectively support the patient. Rehabilitation nurses, for their part, in addition to playing their own specific role, pass on relevant information to the health care team and undeniably participate in ensuring continuity of care.

To explain the concept of interprofessional collaboration, we refer to the National Interprofessional Competency Framework ${ }^{[23]}$. According to this reference, interprofessional collaboration "occurs when learners/practitioners, patients/clients/families and communities develop and maintain interprofessional working relationships that enable optimal health outcomes" (p. 6). "Elements of collaboration include respect, trust, shared decision making, and partnership" 
(p. 8). As such, the nurse's collaborative role within the team has patients' integration and social participation as the objective, with an approach based on the Caring-DCP model, as shown in Figure 2.

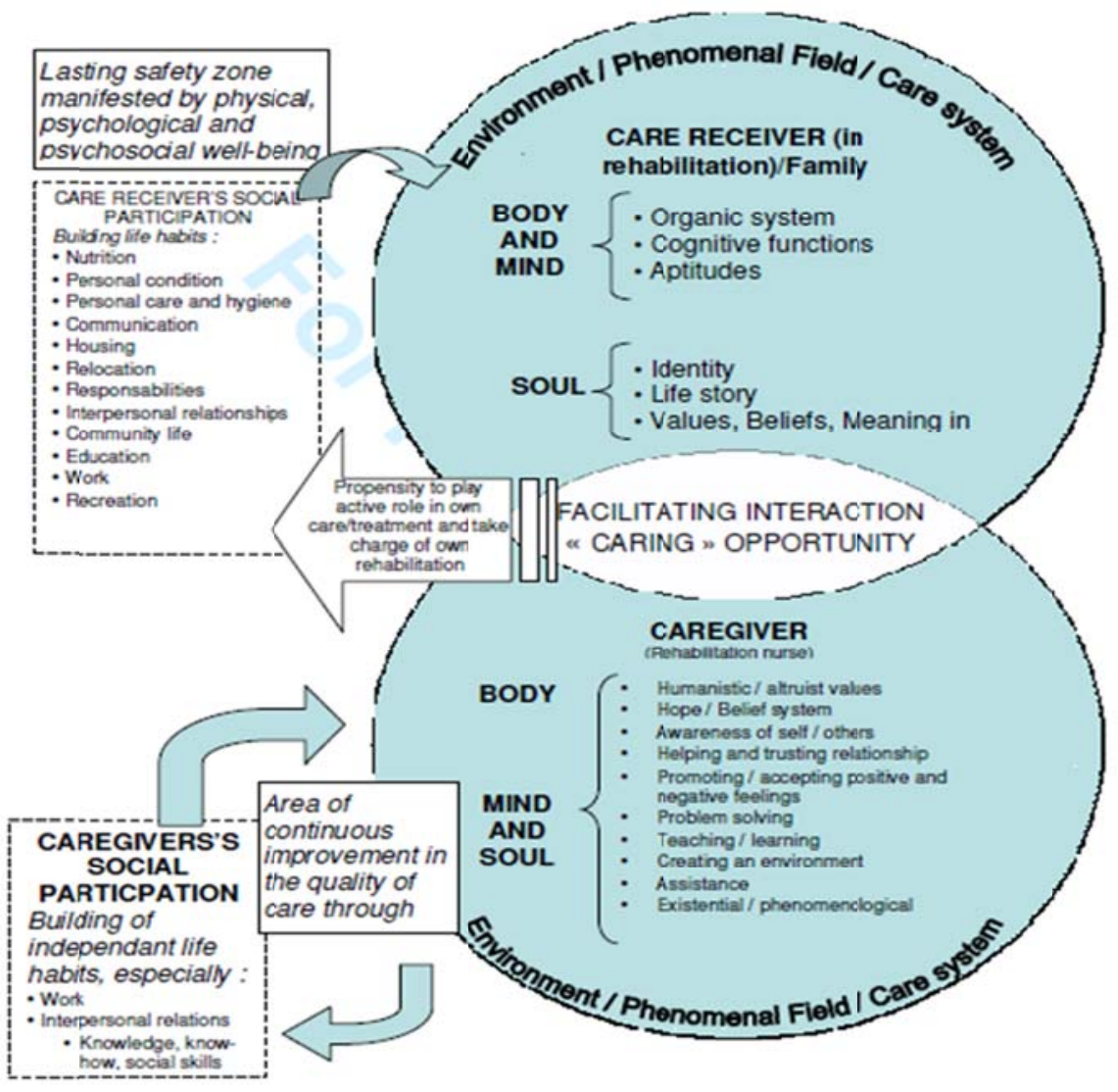

Figure 2. The Caring-DCP Model Applied to Physical Rehabilitation Care ${ }^{\circledR}$ (source: St-Germain et al., 2008a.)

This model represents two people: the caregiver and the care receiver (more holistic term used here talking about the "patient" and including the family as a unit supporting the person), who have organic characteristics (body), cognitive characteristics (mind) and personal and identity characteristics (soul), who each have their own phenomenal field (life experience in environment, care system) and whose life situation has no meaning other than that described by each of them. The caregiver, in this case the nurse, who is in control of his or her own life, accompanies the care receiver, in this case the patient, by considering him or her as a whole person, body, mind and soul. Using an approach based on carative factors, the nurse establishes a professional reciprocal relationship based on trust and closeness ${ }^{[13]}$. This type of relationship brings about a facilitating interaction (for the patient) that is actualized at a specific moment of contact between nurse and patient: the caring opportunity. At this focal point, the nurse better understands what the patient is experiencing and interacts in such a way as to optimally solicit the patient's cooperation and self-actualization. Patients' propensity to play an active role in their own care and treatment and take charge of their own rehabilitation becomes a turning point in achieving social participation. Through active and intensive learning, at their own pace during the rehabilitation, as well as through respect for their unique needs, expectations and aspirations, patients should acquire independent life habits within a stable safety zone that is manifested in their physical, psychological and psychosocial well-being ${ }^{[13]}$. Through this state of well-being, the feedback eventually transforms the patient's phenomenal field - body, mind and soul.

The process of transforming the patient's phenomenal field will itself change the approach the nurse uses. Since the patient can better define his or her own needs and show greater self-determination in helping with the rehabilitation, the nurse is led into a path of continuous improvement of quality of care, guided by carative factors. This process will result in greater professional awareness and will expand the nurse's appreciation of the importance of using enlightened critical judgment, 
being vigilant, continuing to improve skills and being genuine enough to recognize professional limitations. This enhanced professional awareness will motivate the nurse to make a greater commitment to the humanistic and altruistic values that will determine his or her social participation. The social participation of nurses will thus manifest itself through the acquisition of life habits related to work and interpersonal relationships that demonstrate knowledge, know-how and social skills imbued with kindness and professional accountability ${ }^{[13]}$. Finally, nurses' knowledge, know-how and people skills, along with kindness and professional accountability, will close the feedback loop by increasingly orienting their approach towards carative factors, and thereby transforming their phenomenal field.

It should be noted that, throughout these reciprocal caregiver-care receiver transformations, the health care system is also being renewed, revealing a humanistic practice environment in which quality of care and safety for persons in rehabilitation are fundamentally advocated for. In this sense, moving well beyond an exclusive philosophy of nursing care, the Caring-DCP Model Applied to Physical Rehabilitation Care $@$ can become a benchmark for all rehabilitation managers or professionals concerned with providing quality care that also ensures patient safety.

With this key objective in mind, the Caring-DCP Model Applied to Physical Rehabilitation Care $($ was developed to bridge the gap between care and rehabilitation and highlight the holistic nature of nurses' work in this setting.

Moreover, regarding the interdisciplinary work at the IRDPQ, it affects more than 20 different professional titles. The various professionals must work together to achieve the rehabilitation goals of clients with different needs. In this context, the professionals' roles, responsibilities and areas of intervention must be well known and understood by everyone involved. As Boivin ${ }^{[8]}$ notes, a team made up of different professionals including nurses revolves around the patient. The interdisciplinary approach acquires meaning in a process based on the client's lifestyle and social participation. Rehabilitation nursing is guided by the same approach. The process is very coherent. Nurses' participation in the patient's interdisciplinary intervention plan (IIP) is essential, and they must offer care corresponding to the needs identified in the plan during group meetings. Since continuity of care is fundamental to physical rehabilitation, good preparation at interdisciplinary meetings and following an IIP are especially necessary in this context. In addition, given the rehabilitation nurses' clinical role (evaluation, intervention, follow-up, prevention, health education, teaching, coaching, supervision, coordination, liaison, advocacy, implementing medical prescriptions), their participation in the IIP is crucial $^{[8]}$.

To sum up, it is clear that rehabilitation nursing practice needs to be extremely holistic. Applying the Caring-DCP approach is one way of ensuring this outcome. On the other hand, such an approach cannot provide conclusive results without solid interprofessional collaboration among the various professionals who are involved in patients' integration and social participation. The synergy of such teams undeniably constitutes a driver of quality care and ensures patient safety that is a so major issue in the contemporary health care system.

\section{References}

[1] Henderson, V. A. Preserving the essence of nursing in a technological age. Journal of Advanced Nursing. 1980; 5: 245-260. PMid:6900634 http://dx.doi.org/10.1111/j.1365-2648.1980.tb03350.x

[2] Wirotius, J. Histoire de la rééducation. In Encyclopédie médico-chirurgicale. Paris, France: Elsevier Masson; 1999. Available from: http://www.em-consulte.com/article/10150/histoire-de-la-rééducation

[3] Blaxter, M. The meaning of disability: A sociological study of impairment. London, UK: Heinemann Educational Books; 1976. PMid:181354

[4] Barnitt, R., \& Pomeroy, V. A holistic approach to rehabilitation. British Journal of Therapy and Rehabilitation. 1995; 2: 87-92.

[5] Pryor, J., Walker, A., O’Connell, B., \& Worrall-Carter, L. Opting in and opting out: A grounded theory of nursing's contribution to inpatient rehabilitation. Clinical Rehabilitation. 2009; 23: 1124-1135. PMid:19906766

http://dx.doi.org/10.1177/0269215509343233 
[6] Gravel, C. Le défi du monde de la santé: Comment humaniser les soins et les organisations. Quebec, QC: Presses de l’Université du Québec; 2005.

[7] Matter, C., \& Rugraff, P. La fonction infirmière en rééducation-réadaptation. Soins. 2006; 51: 61.

[8] Boivin, B. Au cœur de nos soins infirmiers: la personne. Quebec, QC: Institut de réadaptation en déficience physique de Québec; 2006.

[9] Cara, C. A pragmatic view of Jean Watson's caring theory. International Journal for Human Caring. 2003; 7: 51-61.

[10] Watson, J., \& Foster, R. The Attending Nurse Caring Model ${ }^{\circledR}$ : integrating theory, evidence and advanced caring-healing therapeutics for transforming professional practice. Journal of Clinical Nursing. 2003; 12: 360-365. PMid:12709110 http://dx.doi.org/10.1046/j.1365-2702.2003.00774.x

[11] St-Germain, D., Boivin, B., \& Fougeyrollas, P. Allier le soin infirmier et la réadaptation: un modèle de pratique Caring-Processus de Production du Handicap peut-il faire la différence? Recherche en soins infirmiers. 2008; 95: 57-69. PMid:19195345

[12] St-Germain, D., Boivin, B., \& Fougeyrollas, P. The Caring-Disability Creation Process model: A new way of combining “care” in nursing and "rehabilitation” for better quality of services and patient safety. Disability and Rehabilitation. 2011; 33: $2105-2113$. PMid:21401337 http://dx.doi.org/10.3109/09638288.2011.560330

[13] Watson, J. Nursing: The philosophy and human care. Boston, MA: Little Brown; 1979.

[14] Watson, J. Nursing: Human science and human care: A theory of nursing. Sudbury, MA: Jones \& Bartlett Publishers; 1999.

[15] St-Germain, D., Blais, R., \& Cara, C. La contribution de l'approche de caring des infirmières à la sécurité des patients en réadaptation: une étude novatrice. Recherche en soins infirmiers. 2008; 95: 57-69. PMid:19195345

[16] Long, A. F., Kneafsey, R., Ryan, J., \& Berry, J. The role of the nurse within the multi-professional rehabilitation team. Journal of Advanced Nursing. 2002; 37: 70-78. PMid:11784400 http://dx.doi.org/10.1046/j.1365-2648.2002.02059.x

[17] Kirkevold, M. The role of nursing in the rehabilitation of acute stroke patients: Toward a unified theoretical perspective. Advances in Nursing Science. 1997; 19: 55-64. http://dx.doi.org/10.1097/00012272-199706000-00005

[18] Pryor, J., \& Smith, C. A framework for the role of registered nurses in the specialty practice of rehabilitation nursing in Australia. Journal of Advanced Nursing. 2002; 39: 249-257. PMid:12121525 http://dx.doi.org/10.1046/j.1365-2648.2002.02271.x

[19] Leighton, E., \& Binstock, R. The lost art of caring: A challenge to health professionals, families, communities, and society. Baltimore, MD: Johns Hopkins University Press; 2001.

[20] Pryor, J., \& Buzio, A. Enhancing inpatient rehabilitation through the engagement of patients and nurses. Journal of Advanced Nursing. 2010; 66: 978-987. PMid:20337804 http://dx.doi.org/10.1111/j.1365-2648.2009.05237.x

[21] Hoeman, S. P. Rehabilitation nursing: Prevention, intervention, and outcomes (4th ed.). Philadelphia, PA: Mosby Elsevier; 2008.

[22] Fougeyrollas, P., Cloutier, R., Bergeron, H., Côté, J. \& St-Michel, G. Classification québécoise: Processus de production du handicap. Quebec, QC: Réseau international sur le processus de production du handicap (RIPPH); 1998.

[23] Canadian Interprofessional Health Collaborative - Consortium pancanadien pour l'interprofessionnalisme en santé (CIHC-CPIS). National interprofessional competency framework. Vancouver, BC: CIHC-CPIS; 2010. 